\title{
CONSERVATION OF THE SINCLAIR INN MUSEUM, AND THE PAINTED ROOM ANNAPOLIS ROYAL, NOVA SCOTIA, CANADA
}

\author{
Ann Shaftel ${ }^{a}$, John Ward ${ }^{b}$ \\ ${ }^{a}$ Conservator in Private Practice, Halifax, Nova Scotia, Canada. (info@annshaftel.com) \\ ${ }^{b}$ Preservation Development Advisor, Canadian Conservation Institute - Historic Interiors, 1030 Inner Road, Ottawa, Ontario, \\ Canada. (john.ward@canada.ca)
}

\section{Commission II}

KEY WORDS: Heritage Building, Wood, Murals, Conservation, Preservation, Masonic, Canada

\section{ABSTRACT:}

Conservation of the historic 18 thC. Sinclair Inn Museum, and of the recently discovered late $18^{\text {th }} /$ early 19 thC. unique panoramic wall paintings located in an upstairs room, are co-dependent. This project was carried out with Canadian Conservation Institute (CCI) staff, and Conservator in Private Practice Ann Shaftel. This paper will introduce the Sinclair Inn Museum, outline the CCI murals and building investigations of 2011-15, the mural investigation of 2015-16, which confirmed that the mural extended to all four walls of the function room, now referred to as the Painted Room, and to describe how it has been revealed and conserved to date.

\section{INTRODUCTION / BACKGROUND}

Sited on the waterfront at Annapolis Royal, Nova Scotia, the Sinclair Inn Museum is understood to be the second oldest wood frame building extant in Nova Scotia and Canada and has been dated by dendochronology to c.1710, and is designated provincially and federally. (The oldest known extant wood frame building is the deGannes House, also in Annapolis Royal, which dates to c.1708)

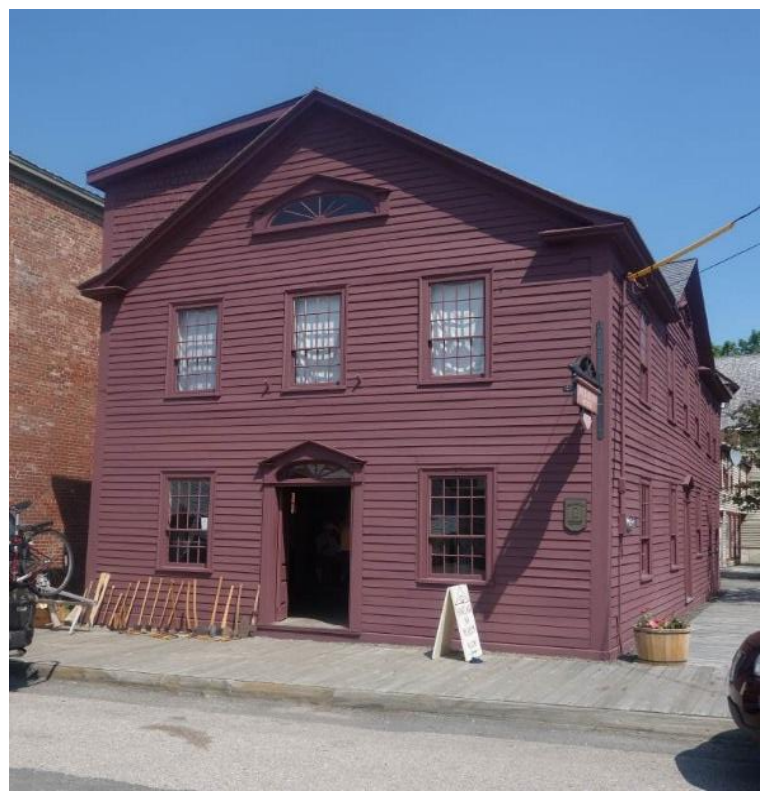

Figure 1: Sinclair Inn Museum, Main entrance façade, Lower George Street, June 2015. Source: CCI

The building is particularly significant for integrating two Acadian period wood frame buildings complete with their walls and floor structures, including the two-storey front section, dating to c.1710, known as the Soullard House which remains on its original site. The Soullard House is recorded to have been licensed as a tavern in 1746. Attached behind it is the single storey frame building known as the Skene House (dated to c.1708 or earlier) which was moved here complete with wattle and daub exterior walls from a nearby site sometime between 1749-81. The building took its current form in c.17812 when it was purchased, enlarged and unified by Frederick and Mary Sinclair, for whom the building is named.

Internally a central stair was added leading to a corridor along the second floor off which were bedrooms or function rooms. The front room over the main entrance façade, which extended the full width of the building was the principal function room, now known as the Painted Room, which is where the painted murals were discovered. Also of note is that the Sinclair Inn is understood to be the meeting place in 1738 of the first Masonic Lodge in the colony of Nova Scotia and thereby of Canada.

The Sinclair Inn functioned as an inn and tavern through till the $20^{\text {th }}$ century. However, the inn was not well maintained. The building deteriorated and eventually closed in the mid-1950s. The ground floor served as a taxi business premises at ground floor level till the 1970 s when it was left vacant.

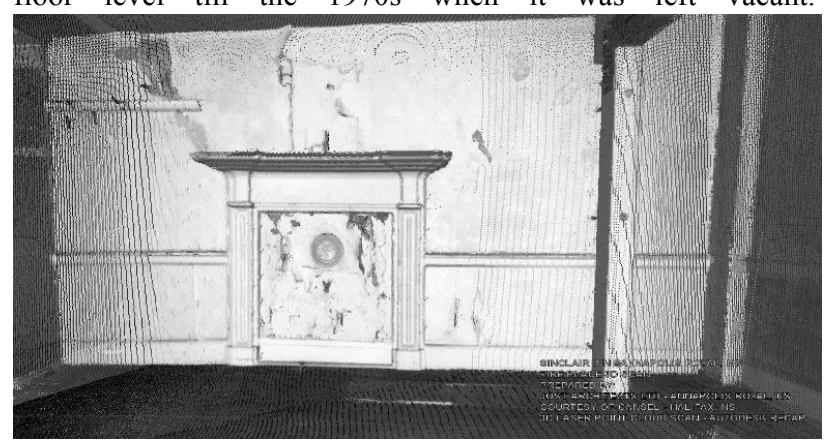

Figure 2: Interior of the Painted Room, 2014, prior to "reveals". Source: Ann Shaftel 


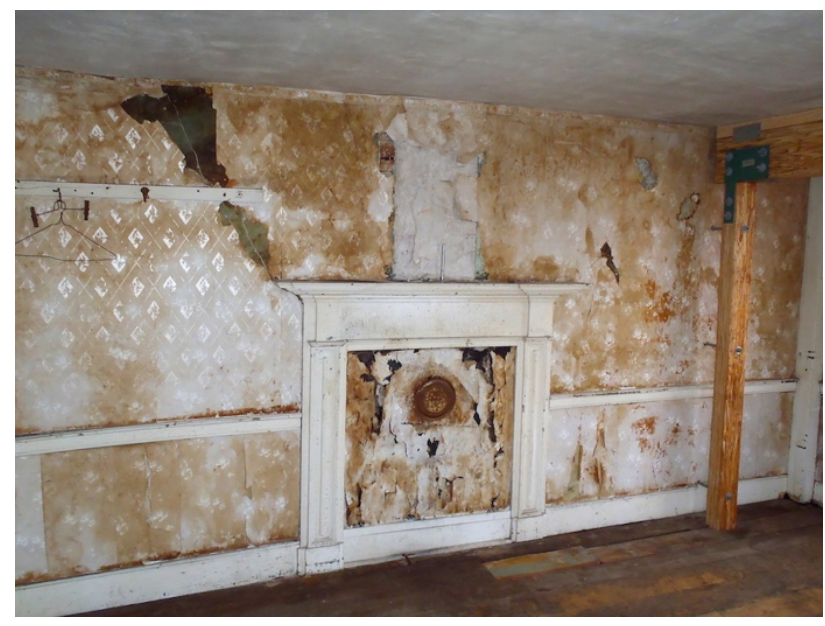

Figure 3: Laser scan of Painted Room east wall by Jost Architects, 2014

In the early 1980s the inn was acquired by Heritage Canada who stabilised the structure and opened it as a historic house type museum. In the 1990's Heritage Canada sold the Sinclair Inn to the Annapolis Heritage Society (AHS) for a token sum, who have maintained and operated the museum ever since and who have undertaken various works to stabilise the building structure, improved its interior displays and interpretation about the building construction and history, and to repair the envelope. Today the building functions as a seasonally operated museum (closed and unheated during the winter). Only the ground floor and basement are accessible to visitors due to the upper floors being in poor condition.
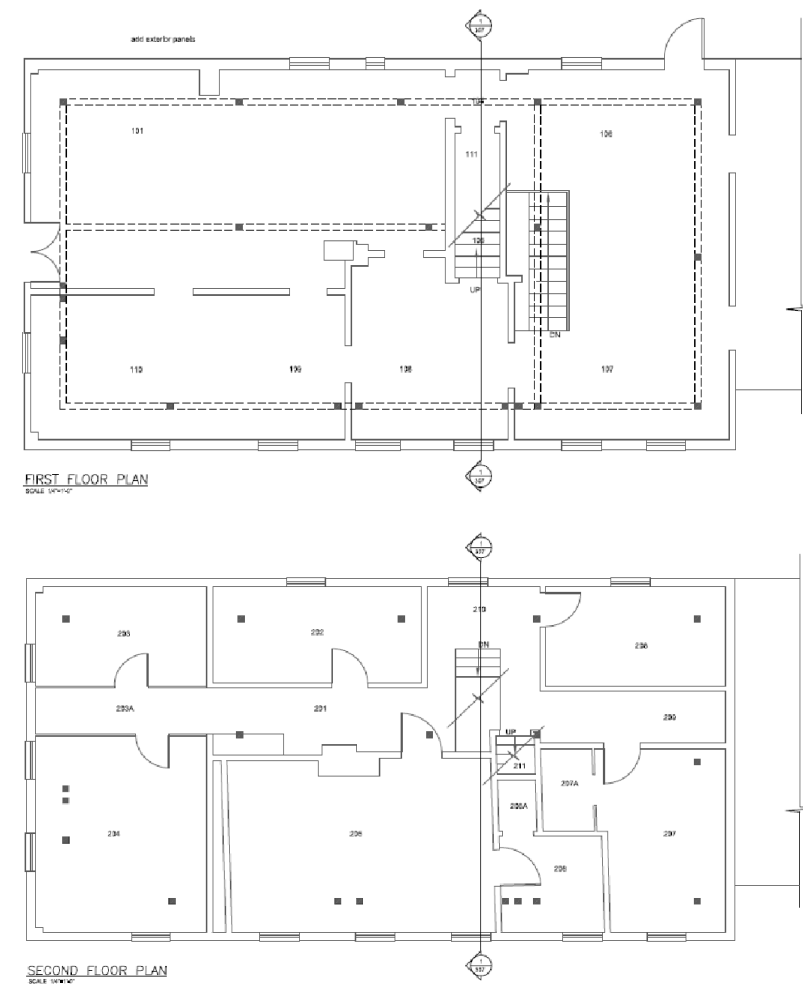

Figure 4: Sinclair Inn Museum Ground and Second Floor Plans showing reinforcing structural upgrades. Plans Prepared by Jost Architects Ltd.

\section{DISCOVERY OF THE PAINTED ROOM WALL MURALS AND INITIAL INVESTIGATIONS c.2008- 2011}

The Painted Room comprises the upper floor of the original c.1710 two-storey Soullard (Acadian), and is at the front section of the building. The original interior layout and location of partition walls and staircase is unclear. At the time when the wall murals were painted, the whole upper floor of the Soullard House was united into a single large rectangular function room (1780s?). At a later date, (late 19thC?) this space was subdivided into a two-room suite with a large drawing room and bedroom. At some point, perhaps during the late $19^{\text {th }} /$ early 20 thC, the two rooms were both used as bedrooms with a corridor in between - creating a north and south room.

In c.2008, a roof leak on the north wall revealed the existence of a large wall mural hidden beneath layers of wallpaper. These wall paintings are the immediate subject of this paper.

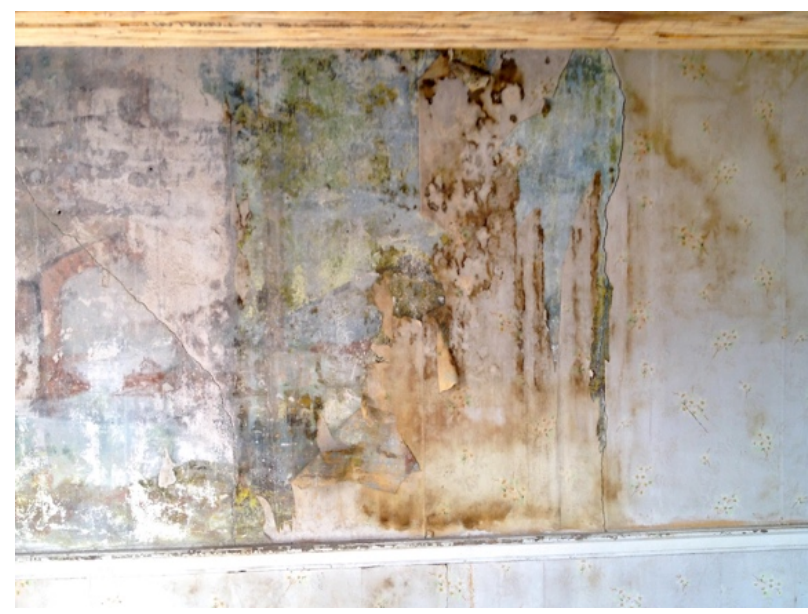

Figure 5: North wall paintings and wallpaper after roof leak. Source: Ann Shaftel

In January 2009, the AHS requested the Canadian Conservation Institute (CCI) to investigate the wall mural and to advise on whether it could be revealed and conserved. A site investigation and facility assessment of the painted room and its interior surfaces was undertaken in October 2011 by James Bourdeau, Manager, Historic Interiors. In brief, the assessment rec $\quad$ hat the AHS follow an incremental phased app 1s revealing and conserving the wall murals inc] silise the plaster finished walls and ceiling by a pla: tion expert, to check the significance of the wal sposed to be removed by a wall paper con to involve a painted murals conservator to loc: $\quad$ zas of loose/detached plaster, and to repair and con plaster walls, for example to fill holes in the pla:

As a second phase, CCI recommended to undertake a full investigation of the murals including suggesting a three-step approach of removing the wallpaper, assess the murals for work required to recover the decorative scheme, and then to develop 
a plan and budget for conservation treatment and restoration. The report also observed that the late $19^{\text {th }}$ or early 20thC subdividing walls within the Painted Room were not significant and would obscure the overall appearance of the room, and were recommended to be carefully removed.

Following the CCI assessment of the Painted Room, in 2014-15 the AHS engaged Ann Shaftel, a professionally trained and experienced conservator based in Halifax Nova Scotia, to investigate, reveal and conserve the Painted Room wall murals. Ann Shaftel worked to create a series of small windows or "reveals" in the wallpaper on all interior walls of the Painted Room to check the full extent of the murals and the feasibility of revealing them. She created a methodology for removal of wallpaper without the use of toxic solvents in a public museum. She also mapped out sections of the room, below the chair rail, where lead paint completely covered both the wallpaper and original murals. This in turn would enable the AHS Building Committee and its funders, the Atlantic Canada Opportunities Association (ACOA), the Department of Canadian Heritage and Parks Canada to decide whether to fund the removal of all the wallpaper to fully reveal the murals hidden beneath.

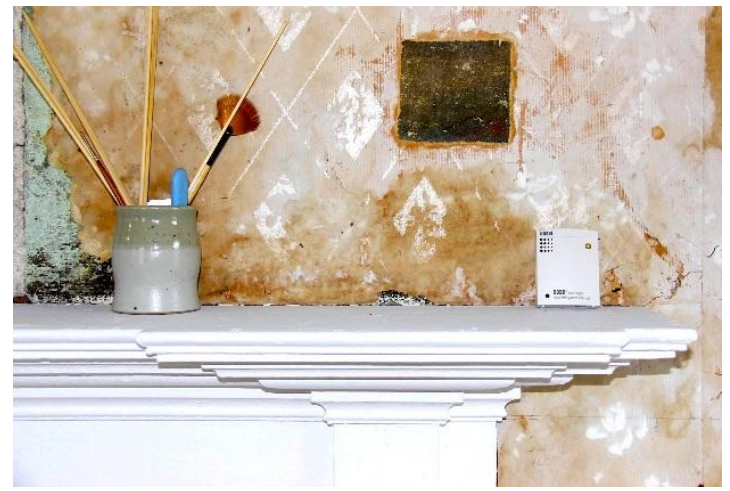

Figure 6: Conservator revealing the painting underneath the wallpaper above the fireplace. Source: Ann Shaftel

At this time, it was unclear to the conservator and the funding partners whether the water leak issue at the north wall had been addressed. Also, a preliminary conservation plan was proposed by the AHS Building Committee based on the CCI recommendations of 2011 which focused on removing the partition walls added in the late $19^{\text {th }} /$ early 20 thC. within the Painted Room, stabilizing the plaster walls, reinforcing the second-floor wood structure for use by visitors, adjusting the location of support columns if they interfered with door openings, restoring and converting an adjacent large bedroom into an audio-visual interpretation room, and insulating the Painted Room and providing it with a heating/cooling HVAC unit to provide a stable environment for the long-term conservation of the wall murals.

Subsequent investigations in 2014-15 by Ann Shaftel, conservator, revealed that the panoramic wall murals extended to all four walls of the original principal function room on the second floor, a very unexpected, rare, and exciting find.

Following the confirmation of the extent of the wall murals at the Sinclair Inn, the AHS sought funding from the Department of Canadian Heritage and the ACOA to engage Ann Shaftel to remove the wallpaper to fully reveal the paintings. The proposed scope of work also included for structural stabilisation and levelling of the second floor as required, providing appropriate environmental control to conserve the wall murals, and to undertake work on the stairs to facilitate public access.

\section{CCI FACILITY ASSESSMENT 2015}

At the request of the Department of Canadian Heritage, the Parks Canada Agency and the AHS, in 2015, CCI undertook a second more holistic facility assessment of the Sinclair Inn Museum to:

- reconfirm the provincial and national heritage significance of the Sinclair Inn Museum

- confirm that the Sinclair Inn external envelope renovated in 2011-12 was in sound condition, that the cause of the water infiltration had been addressed;

- review a proposal by the Annapolis Royal Historic Association to undertake work to enable the murals to be fully revealed, conserved and be able to be visited by the public.

In June 2015, Canadian Conservation Institute facility assessment staff members Paul Marcon, Conservation Engineer, Preservation Services, and John Ward, Preservation Development Advisor, Historic Interiors, undertook a site visit and met with all parties involved in conserving the Sinclair Inn Museum and the wall mural restoration, as well as with building code and fire inspectors.

Following a visual inspection of the Sinclair Inn Museum, reviewing background information and meeting experts in built heritage working with the AHS, it was concurred that the Sinclair Inn was a very significant historic building, and that conservation work undertaken by the AHS since the late 1990s including stabilisation of the building's wood structure and floors, and the external envelope renovation had been carefully undertaken and that there was no evidence observed of any further water ingress.

However, additional issues were observed including: Fire Risk - although a fire detection system was installed which was connected to a $24 / 7$ monitoring centre which normally would be adequate for such a building, it was observed that the building was of all wood construction and highly combustible, and that the fire alarm may not function well in very cold winter temperatures. As such, the installation of an early warning aspiration type fire detection system was recommended to enable any fire to be detected at its embryonic stage to minimise any delay in response by the emergency services. In the longer term, a fire suppression system was recommended, if possible a water mist/nitrogen system which if activated by an early warning fire detection system could extinguish an internal fire at a very early stage with minimum of damage.

Environmental control: It was of concern that the painted room with its wall murals is an integral part of a larger historic building and that a more holistic approach towards conserving the building as a whole was recommended to be taken rather than insulating and heating the room in isolation. The Annapolis Royal Historic Association raised that there was 
little operational funding and that the cost of heating the whole building was prohibitive without additional financial support. As such, CCI agreed to explore and advise on economic operational approaches towards improved environmental control without significant increase in operating costs. In the final report CCI advised as follows:

- Basement crawl space: install an industrial grade refrigeration type dehumidifier (equipped with condensate pumps and remote wired controlled humidistats with a maximum $65 \%$ set point to address high moisture and relative humidity levels in this space between the spring and fall.

- Painted Room: Recommend not to insulate this room separately to the rest of the building; rather, leave the room unheated and uninsulated, and to environmentally control the interior relative humidity to be consistent with ASHRAE Class of Control "C" ie. $25-75 \% \mathrm{RH}$ through introducing mild heating in the room in the winter season (3-4 degrees C).

- That any mechanical systems installed should be carefully considered and installed to minimise the visual and physical impact on the building and its historic interiors, particularly in the Painted Room itself (e.g. Install equipment if possible at ceiling level or in the attic space above).

- Electrical: To reduce risk of electrical fires, a number of electric extensions were observed which could be minimised with additional or relocated power sockets, and installation of a higher quality electric intake was recommended in the electrical room.

Light - Natural: In the painted room, advise to explore installing UV light absorbent film on windows (unless glass is historic) and to introduce curtains and blinds to reduce/limit light levels on wall and mural surfaces

Lighting - Artificial: Recommend installing LED lighting to reduce operating costs.

Second Floor Visitor Access; Second floor and staircase repair and reinforcement: In discussion with building and fire code officers this could be addressed by modifying a side door at the bottom of the stairs to be a fire egress route, repairing loose stair handrails and newel post, adding an additional handrail, and limiting visitor numbers allowed at second floor level at any one time.

Painted Room plaster wall stabilisation: Some wall surfaces were uneven, damaged and curling at edges. It was advised that the walls should be stabilised and repaired by AHS as required (CCI facility assessment of 2011) prior to mural conservation, and that stabilisation methodology should be discussed and agreed with the mural conservator to minimise impact and loss of paint.

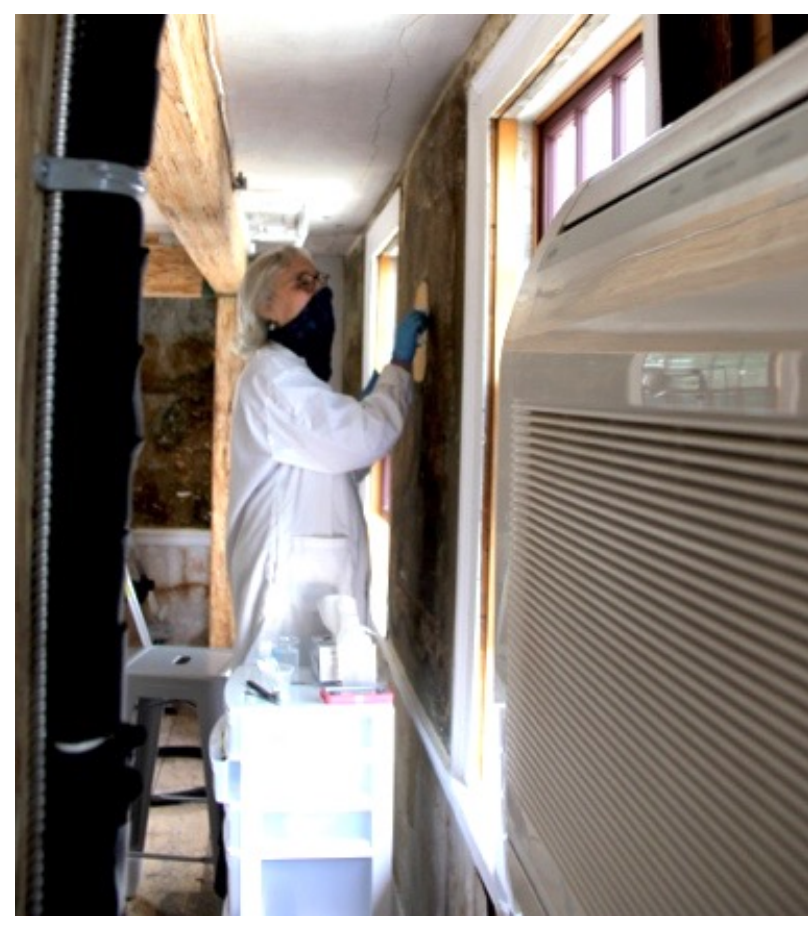

Figure 7: Conservator working next to AHS-installed environmental control unit.

\section{Sinclair Inn Painted Room Panoramic Wall Murals -} Revealing, Stabilizing and Inpainting the Murals: 2016

This scope of this conservation project had definite constraints in terms of budget, the remote location of Annapolis Royal, as well as on-site technical challenges including working on high lead content wall murals in an historic building with mold and pests (mice).

The use of enhanced digital images during conservation treatment enabled the identification of cracks, holes, and other damage to the plaster walls which serve as the painting's support and thereby an overall understanding of the stability of the walls and plaster and stabilization work required.

Included in the conservator's digital toolbox were laser scans, 3D imaging of the room during conservation treatment, postcapture processing of "working" digital images, the use of UV specific light source as well as use of a portable microscope viewed through a MacBookAir for viewing details through white, IR, and UV light sources.

\subsection{Documentation}

Documentation is an important part of any conservation treatment. All wall murals in the Painted Room were documented and digitally recorded from the outset of the investigation work, which continued through to completion of the complicated conservation treatment undertaken in 2016. A significant number of images were captured at the "before, "during" and "after" stages as "working images" for reference during all phases of the treatment and for the final report, with a Canon professional camera and iPhone.

The paint layers in the Painted Room were in fair to poor condition, resulting from many factors including: location 
inside a room used as a meeting/function room, bedroom, etc.; past construction and redecorating in the room, pasting and removal of several layers of wallpaper, and shifting environmental conditions in an uninsulated building; occasional water infiltration.

There are cracks and divots overall in the plaster of the walls that form the paintings' support, causing damage to the paint layers. This damage was present but hidden below the wallpaper layers, or had been exposed where the paper was removed by roof leaks or by construction. Past and more recent construction and painting also damaged the wall murals.

It was important to document the condition of the walls and paint layers before conservation work began, and during the work when removal of wallpaper exposed and revealed previously hidden significant structural weakness and damage, blanching and discolouration of the plaster, and damaged paint layers.

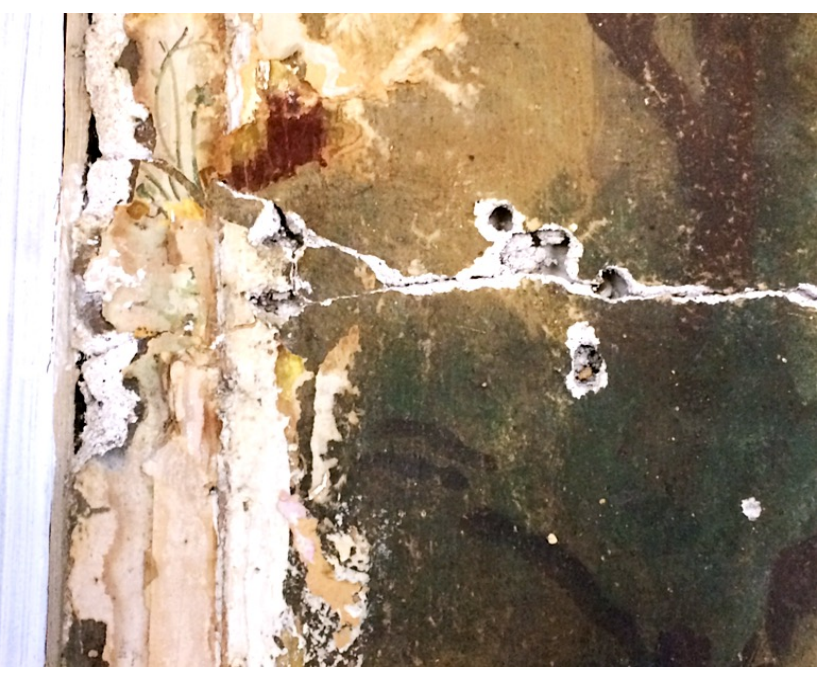

Fig 8: Documentation of condition. Source: Ann Shaftel

The condition of the paintings is also a result of the artists' painting technique. Investigations suggest that the wall murals were painted by different artists at two or more times, rather than by a master artist and apprentices painting at one time. On every wall, the conservator found several layers of painting on top of each other. As the binder and pigments changed over time, and as they became damaged, they may have become either translucent (??). For example, as shown below, a mountainous landscape is painted over the outline of a classical Greek style pillar with an ionic capital (left image, column to right hand side), and then another mountain is painted on top of the original mountain. Therefore, detailed documentation was essential.

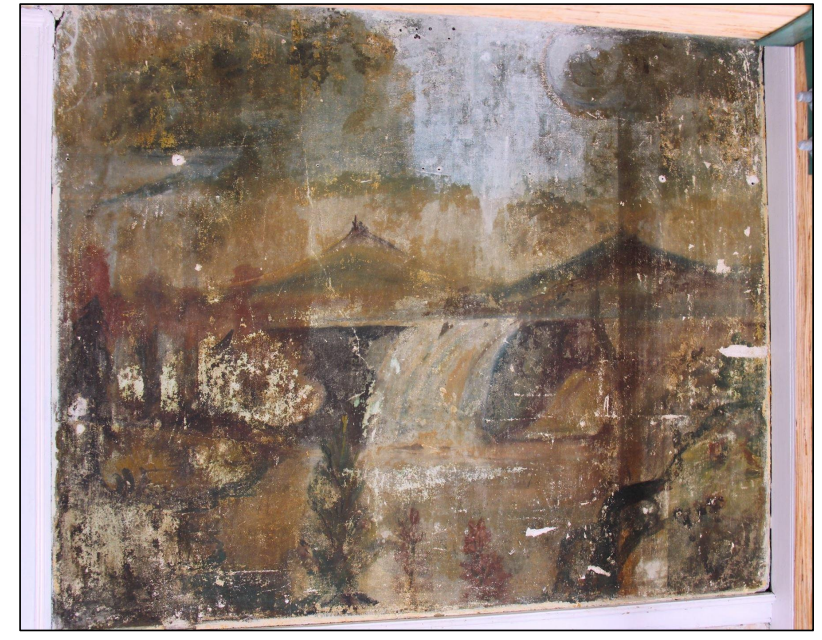

Figure 9: South wall layers of paintings. Source: Ann Shaftel

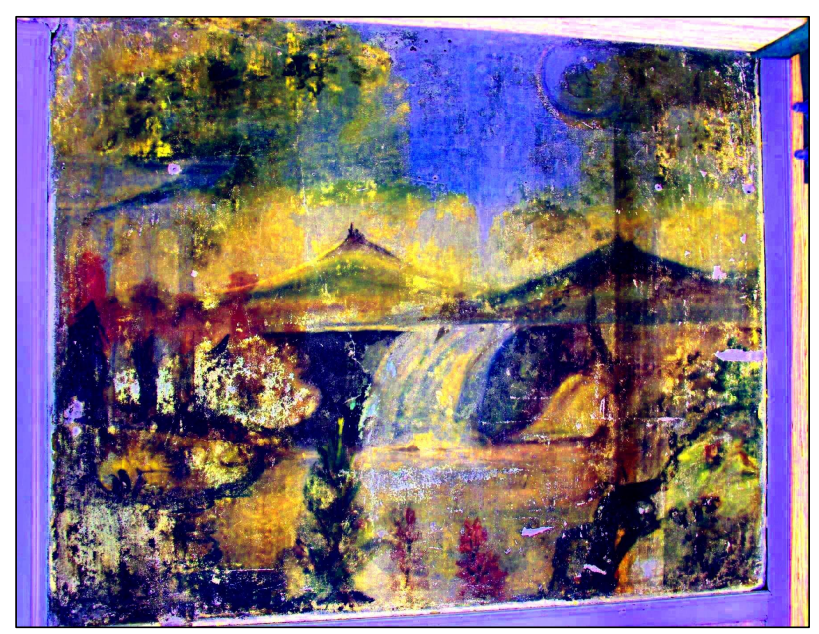

Figure 10: Post capture enhancement with iDStretch further reveals work of various artists. Source: Ann Shaftel

The condition of each section of each wall differs also due to the qualities of the paint layers used by different artists at different times. In general, the pigments are bound into a paint film with a "drying oil" binder, which was very traditional for the times. Itinerant painters, however, often used whatever oils were available on site.

The high lead content of the paint employed for the wall murals was also a cause of concern, and required the conservation team to wear gloves and face masks. However, their protection was not complete enough and one team member had elevated lead levels in her blood after working there for several months.

Some of these wall mural images were also subject to postcapture analysis by several processes, including iDStretch. 


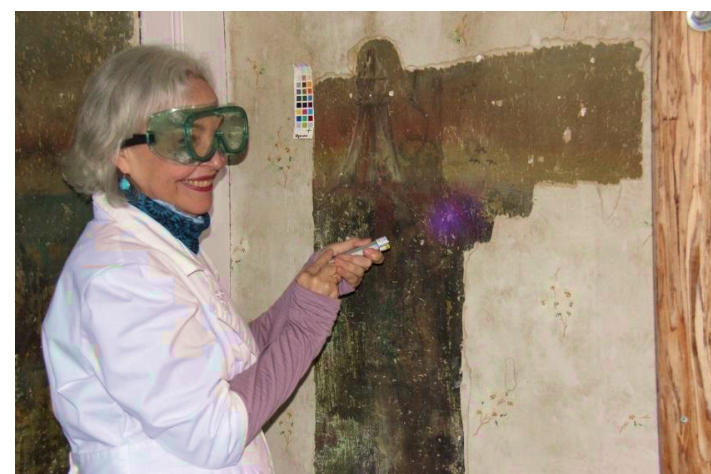

Fig 10: A dedicated UV light source was also utilized (with use of protective eye goggles).

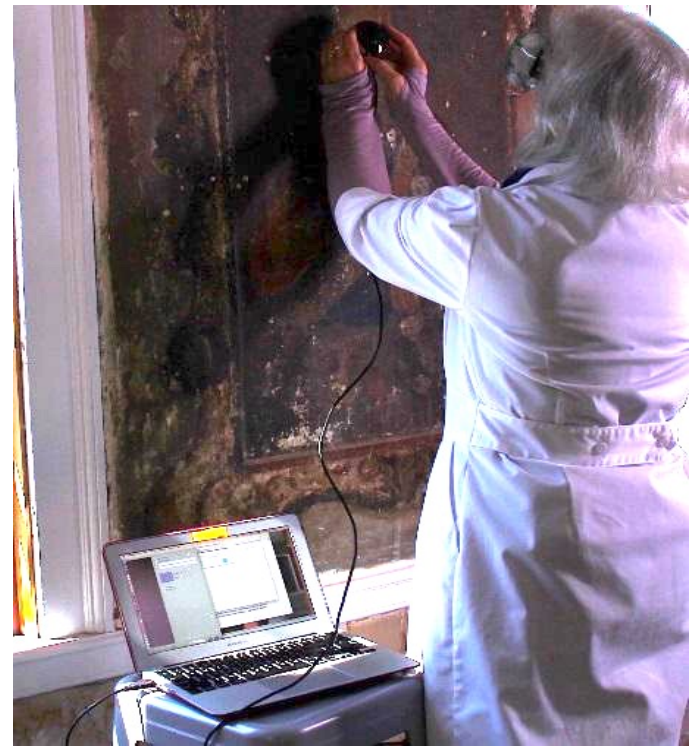

Fig 11: Examination included use of a digital microscope with white, ultraviolet, and infrared light sources. For this conservation project, the Zarbeco MISC_MP2EF-WUVIR was utilized.

Condition mapping is an important part of the documentation. Some of the terms used for Condition Mapping include: divot, crack, damage from roof leak, smear of lead paint from woodwork, newer acrylic or oil paint from woodwork, plaster residue, scratches from historic wallpaper removal previous to repeated wallpaper application, layers of painting, and lines of join of wallpaper segments.

After the initial removal of layers of wallpaper, and before consolidation of divots and fine cleaning of paint layers, where possible, the painted walls were further mapped to document the condition of the walls and the paintings. Each section of each wall was photographed in ambient light, from several angles. The digital images were processed first by converting them to black and white, and then increasing the contrast and saturation levels. The images were then printed and attached to display boards, where the types of damage were described. The display boards were placed in front of the corresponding wall. These condition mapping images served as a reference during further conservation work, and can be used in the future to educate visitors and researchers.

Documentation included recording the temperature, relative humidity, and light levels in the Painted Room as work proceeded, as monitored by a HOBO data logger. The environmental conditions were documented with these data loggers from 2014 onwards. For 2016 one data logger was placed in June on the window of the west wall, and one was placed on the mantel and the conservator included these readings in her reports.

The conservator also measured light level readings in the room in daytime sunlight, in the spotlights present at time of work, and during videographer's lights.

The conservator purchased a digital picture frame to create an educational and informative digital picture sequence. This was designed so that a visitor standing in the middle of the room could view progress on each wall while having time to glance at the wall as it was at the moment they were viewing, and compare this with images through stages of conservation treatment.

The Sinclair Inn wall painting conservation project was well researched, well thought-out, well supported informationally by the larger conservation community, well supported by the local heritage society and town members, and financially supported by government and private funders. It combined up-to-date scientific research, professional hands-on treatment, with cultural tourism potential.

\section{CONCLUSION}

The highest professional standards were followed for this hands-on conservation project. Now, the future of the Painted Room murals depends on their protection by the Annapolis Heritage Society.

This conservation treatment was a significant project - to reveal the paintings and to enable the public to visit and view them - and represents an important investment by the Annapolis Heritage Society and its funding partners. The future condition of The Sinclair Inn and its Painted Room is now the responsibility of Annapolis Heritage Society and citizens of Annapolis Royal. As such it is important to protect the paintings when undertaking additional construction work in the building, and using it for Halloween and other functions. It is also recognized that facilitating tourist access needs to be carefully managed so that visitors can do so safely without causing damage to the fragile painted surfaces.

In regard to the technologies employed by the conservation team to investigate the condition of the plaster walls of the Painted Room and the wall murals throughout the project, all have demonstrated their usefulness in terms of identifying condition issues and enabling an understanding of how the murals were painted, and altered, over time.

\section{ATHORS BIOS}

A.Shaftel, MA, MSc Fellow International Institute for Conservation, Fellow American Institute for Conservation, Canadian Association of Professional Conservators, ICOM- 
Canada, ICOMOS-Canada

J.Ward, Preservation Development Advisor, Canadian Conservation Institute

For further information on the conservation work in the Sinclair Inn Museum Painted Room wall murals, contact: info@annshaftel.com

\section{ACKNOWLEDGEMENTS}

Paul Marcon, Jon Domagala, Claire Heisler, Erica Allanach, Jay Heisler, Emma Hartman, Scott Haskins, Annapolis Heritage Society, CCI, Prof. Christa Brosseau, interns, and colleagues.

\section{SOURCES}

Annapolis Heritage Society - Sinclair Inn Museum web site: http://www.annapolisheritagesociety.com/museums/sinclairdirections.html

CCI report 127794: Facility Assessment for the Sinclair Inn Museum, 14 October 2015, Ottawa, Canada

CCI Report 100351, Assessment of the Soullard House Painted Room, Sinclair Inn National Historic Site

MAD Lab, Mount Allison University, Department of Geography, 2005. Mad Lab Report 2005-03:

Dendroarchaeological investigation of the Sinclair Inn, Annapolis Royal, Nova Scotia

Moody, Barry, 1982: The Sinclair Inn, Annapolis Royal ORIGINS to 1781 